\title{
Heavy Metal Contamination and Its Environmental Risk Assessment in Surface Sediments from Lake Dongting, People's Republic of China
}

\author{
Y. Qian, M. H. Zheng, L. Gao, B. Zhang, W. Liu, W. Jiao, X. Zhao, K. Xiao \\ Key Laboratory of Environmental Chemistry and Ecotoxicology, Research Center for \\ Eco-Environmental Sciences, Chinese Academy of Sciences, Post Office Box 2871, \\ Beijing 100085, People's Republic of China
}

Received: 20 October 2004/Accepted: 27 April 2005

Negative effects of the environmental pollution of heavy metals on human health continue to be acute public concerns. As important sinks and sources for various heavy metals, sediments constitute a reservoir of bio-available trace metal elements and also play a significant role in the remobilization of contaminants in aquatic systems under favorable conditions, in interactions between water and sediment and in geo-chemical cycles. The direct transfer of heavy metals from sediments to organisms is now considered to be a major route of exposure for many species (Zoumis et al., 2001). Studies on heavy metals in sediments of rivers, lakes and seas have been a major environmental focus especially in the last decade.

Lake Dongting (shorten as Lake-DT) covering a large surface area around 3000 $\mathrm{km}^{2}$, is located in Hunan Province in the south of China and connects the Yangtze River, the longest river of China. Lake-DT is the second-largest freshwater lake in China and plays an extreme important role in supporting many life forms, water supply for agriculture, aquatic product culture, fisheries, and it is also a good source of water for drinking water production by municipal water works and industry manufacture. In Lake-DT and the neighboring areas, agriculture and breed aquatics develop rapidly in Hunan. Hunan is famous for her abundant metal mineral resources such as lead, zinc, copper, vanadium etc, and there are varies scale factories engaging in metal mining and metallurgy around Lake-DT region. With the accelerated development of the industries of metal mining, metallurgy and manufacture in this region, the possible heavy metal pollution in Lake-DT has become an acute concern by the public. The status of the heavy metal contamination in the lake and its eco-environmental risk are not known well and reports on the heavy metal contamination in sediments from Lake-DT have not been seen.

The objective of this study was to study the pollution status of heavy metals in the sediments of Lake-DT and to assess its ecological and environmental risk, as a contribution to the knowledge and rational management of the lake and region around it in the future. 


\section{MATERIALS AND METHODS}

Deionized water supplied by EASYpure LF System (18 M $\Omega$ ) (Model D7382-33, Barnstead Thermolyne, USA) was used throughout. Super pure nitric acid, hydrogen peroxide and hydrofluoric acid (Beijing Chemical Factory, China) were used for wet digestion. Atomic emission spectrometry standards for $\mathrm{V}, \mathrm{Cr}, \mathrm{Mn}, \mathrm{Co}$, $\mathrm{Ni}, \mathrm{Cu}, \mathrm{Zn}, \mathrm{Cd}, \mathrm{As}$ and $\mathrm{Pb}$ (National Research Centre for Certified Reference Materials, Beijing, China) were used in preparation of calibration solution for ICP-OES analysis.

Four main rivers (Lishui River, Yuang River, Zi River and Xiang River) flowing through the major economic areas in Hunan province connect Lake-DT from the west, south and east (see Figure 1). The altitudes of the west, south and east regions with the exception of the north around Lake-DT are all higher than that of the lake, so the water from the collecting rivers pours into Lake-DT, is retarded by the lake, and flows into Yangtze River finally. Eight sampling locations (S1-S8) selected in Lake-DT and their geographic positions are shown in Figure 1. S1, S4, $\mathrm{S} 5, \mathrm{~S} 6$ and S7 are close to the inlets of the four main rivers converging into Lake-DT. S2, S3 and S8 lie at the body lake area. The samples were collected in March, 2004.

Surface sediment samples from the eight sampling locations were collected from the bottom about $1-5 \mathrm{~cm}$ deep of Lake-DT using the special device used by the lake and ocean researchers. The wet sediments were sealed in PTFE bags and refrigerated $\left(-4^{\circ} \mathrm{C}\right)$ immediately to avoid any adverse changes. The samples were freeze-dried in vacuum at $-46^{\circ} \mathrm{C}$ for $36 \mathrm{~h}$, grinded evenly and sieved with a screen of 100 meshes before the digestion. The digestion of about $0.1 \mathrm{~g}$ dried samples weighed precisely was performed at about $170^{\circ} \mathrm{C}$ for $24 \mathrm{~h}$ by using a mixture of 2 $\mathrm{mL} \mathrm{HNO}_{3}, 2 \mathrm{~mL} \mathrm{H}_{2} \mathrm{O}_{2}$ and $0.5 \mathrm{~mL} \mathrm{HF}$ to obtain the total content of element in sediments. After digestion, the solutions were filtrated and diluted to a final volume of $25 \mathrm{~mL}$ carefully for ICP-OES analysis. All the glass containers used were soaked in $50 \% \mathrm{HNO}_{3}(\mathrm{~V} / \mathrm{V})$ and rinsed with deionized water.

Inductively coupled plasma optical emission spectrometer (ICP-OES) analysis was performed on the equipment (Optima $2000 \mathrm{DV}$, Perkin Elmer, USA) to determine ten heavy metal elements $(\mathrm{Zn}, \mathrm{Cu}, \mathrm{Pb}, \mathrm{Cr}, \mathrm{Cd}, \mathrm{Ni}, \mathrm{Mn}, \mathrm{V}, \mathrm{Co}$ and $\mathrm{As})$. Instrumental conditions were optimized to obtain sufficient sensitivity and precision. ICP instrumental conditions: forward power $(1.15 \mathrm{~kW})$, plasma gas flow (15 L.min $\left.{ }^{-1}\right)$, auxiliary gas flow $\left(1.0 \mathrm{~L} \cdot \mathrm{min}^{-1}\right)$, nebulizer pressure (30 psi), sample uptake rate $1.5 \mathrm{~mL} \cdot \mathrm{min}^{-1}$, nebulizer type (Scott-type), spray chamber (Scott-type), observation height $(15 \mathrm{~mm})$, integration time (1 6 s). 


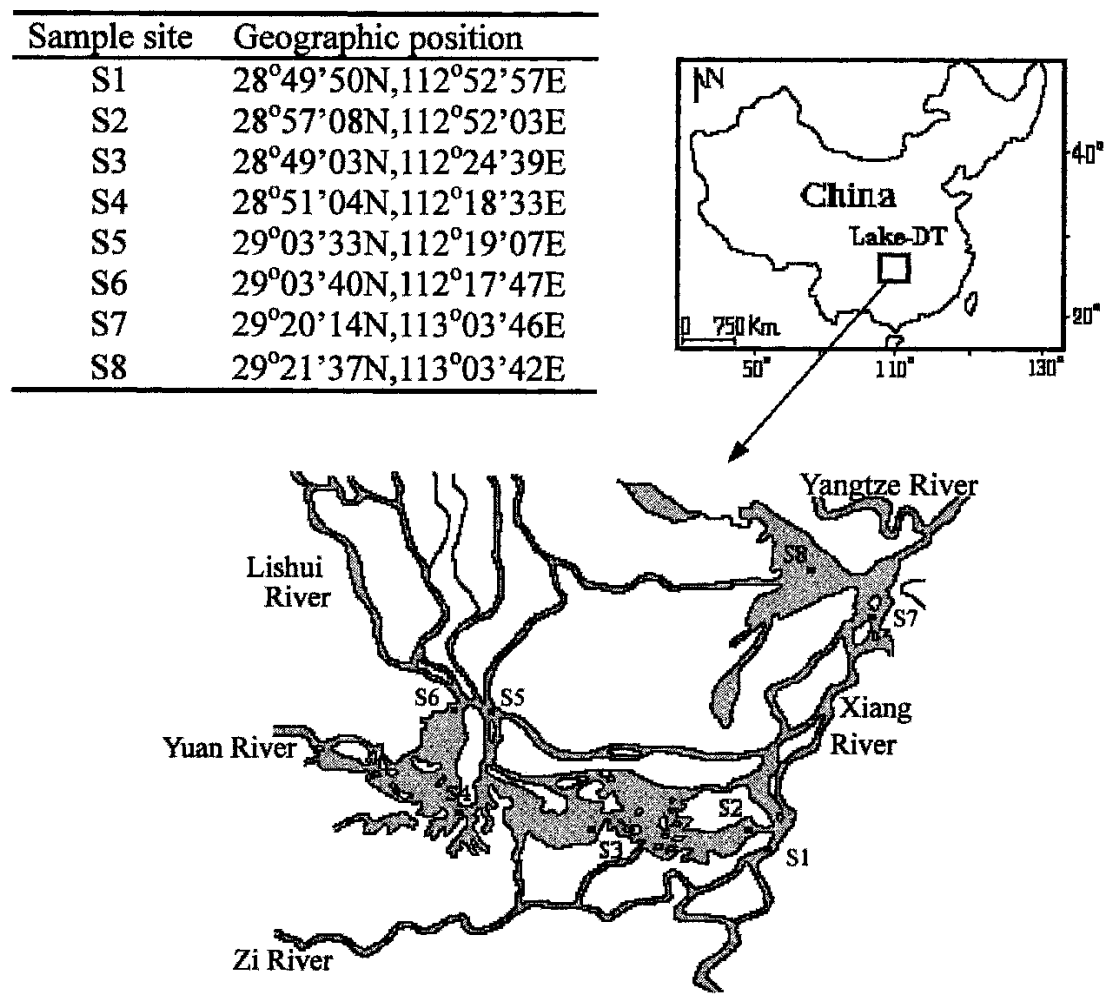

Figure 1. Geographical locations of sampling sites (scale 1:350000).

The limit of quantification (LOQ), recovery, relative standard deviations (R.S.D.) of each metal element and chosen wavelengths of ICP-OES are shown in Table 1. The external calibration method was used with the calibration solutions prepared

Table 1. Limit of quantification of each metal element and conditions of ICP-OES.

\begin{tabular}{ccccc}
\hline Element & Recovery & R.S.D. (n=5) & $\begin{array}{c}\text { Wavelength } \\
(\mathrm{nm})\end{array}$ & LOQ (ng/g) \\
\hline $\mathrm{Zn}$ & 94.81 & 1.5 & 206.20 & 0.2 \\
$\mathrm{Cu}$ & 105.13 & 1.9 & 327.39 & 0.4 \\
$\mathrm{~Pb}$ & 95.66 & 0.65 & 220.35 & 1.0 \\
$\mathrm{Cr}$ & 97.71 & 0.71 & 267.71 & 0.2 \\
$\mathrm{Cd}$ & 123.59 & 0.92 & 228.80 & 0.1 \\
$\mathrm{Ni}$ & 103.61 & 1.2 & 231.60 & 0.5 \\
$\mathrm{Mn}$ & 107.63 & 1.0 & 257.61 & 0.1 \\
$\mathrm{~V}$ & 101.47 & 2.9 & 292.46 & 0.5 \\
$\mathrm{Co}$ & 98.65 & 0.89 & 228.61 & 0.2 \\
$\mathrm{As}$ & 109.75 & 19.3 & 193.69 & 2.0 \\
\hline
\end{tabular}


from dilution of the standard solution, and the concentrations of elements were ranged in 0-1000 $\mathrm{ng} / \mathrm{ml}$. A blank experiment was run under the same experimental conditions to avoid any contamination. All the experiments were carried out twice.

\section{RESULTS AND DISCUSSION}

There are many metal mines and factories specialized at metal mining, metallurgy and manufacture around Lake-DT region. Taken as an example, one large-scale enterprise of lead, zinc, copper and arsenic located at the side of Xiang River is specialized at not only mill run and mining but also metallurgy, which is called as the cradle of Chinese lead and zinc industry. According to the statistics, the amounts of toxic matters emitted into Lake-DT are tremendous, for example 0.11 $\mathrm{t} \mathrm{Cd}, 22.35 \mathrm{t} \mathrm{As}, 16.20 \mathrm{t} \mathrm{Pb}$ and $4.6 \mathrm{t} \mathrm{Cr}$ are discharged into Lake-DT region each year (Tu, 2001). The concentrations of ten heavy metal elements in sediments from Lake-DT are shown in Table 2. Compared to the referenced standards of the ten metal elements in sediments in China (Zhu and Zang, 2001), the contents of most metals studied are much higher than their standard values, and the contamination of $\mathrm{Zn}, \mathrm{Pb}, \mathrm{Cu}, \mathrm{V}$ and $\mathrm{As}$ mined and manufactured largely in Lake-DT region is more serious and universal than that of other metals. Moreover, the concentrations of $\mathrm{Zn}, \mathrm{Pb}$ and $\mathrm{Cu}$ at sites closing to the inlets of the rivers connecting to Lake-DT such as S1, S6 and S7 are relatively higher than that of other sites. It can be found that Lake-DT is seriously contaminated by heavy metals, the contamination of heavy metal probably relates to the discharging of the industries around Lake-DT engaged in metal mining, metallurgy and manufacture.

Table 2. Concentrations ( $\mathrm{mg} / \mathrm{kg}$ dry weight) of heavy metal elements in sediments from Lake-DT.

\begin{tabular}{ccccccccc}
\hline & $\mathrm{S} 1$ & $\mathrm{~S} 2$ & $\mathrm{~S} 3$ & $\mathrm{~S} 4$ & $\mathrm{~S} 5$ & $\mathrm{~S} 6$ & $\mathrm{~S} 7$ & $\mathrm{~S} 8$ \\
\hline $\mathrm{Cu}$ & 77 & 68 & 28 & 52 & 75 & 16 & 79 & 24 \\
$\mathrm{Zn}$ & 4487 & 314 & 5403 & 819 & 1173 & 8948 & 7915 & 545 \\
$\mathrm{Co}$ & 19 & 9.86 & 16 & 16 & 18 & 12 & 16 & 7.38 \\
$\mathrm{Ni}$ & 42 & 9.38 & 14 & 21 & 21 & 12 & 28 & $\mathrm{ND}$ \\
$\mathrm{Mn}$ & 3464 & 1073 & 1274 & 1211 & 894 & 778 & 1665 & 695 \\
$\mathrm{~V}$ & 163 & 71 & 7.64 & 123 & 105 & 133 & 153 & 42 \\
$\mathrm{As}$ & $\mathrm{ND}$ & $\mathrm{ND}$ & 62 & 232 & 218 & 294 & $\mathrm{ND}$ & 71 \\
$\mathrm{Cr}$ & 112 & 64 & 70 & 80 & 82 & 64 & 90 & 36 \\
$\mathrm{Cd}$ & 17 & $\mathrm{ND}$ & 3.59 & $\mathrm{ND}$ & $\mathrm{ND}$ & 12 & $\mathrm{ND}$ & $\mathrm{ND}$ \\
$\mathrm{Pb}$ & 206 & 25 & 123 & $\mathrm{ND}$ & 7.28 & 197 & 204 & $\mathrm{ND}$ \\
\hline
\end{tabular}

Note: ND is not detected.

Long et al. (1995) reviewed and screened many publications for the assessment on 
the biological adverse effects of trace heavy metals in sediments. Using these data, two guideline values (ERL and ERM) were suggested for nine trace metals. The lower 10 th percentile of the effects data for each chemical was identified and referred to as the effects range-low (ERL). The median, or 50 th percentile of the effects was identified and referred to as the effects range-median (ERM). The guideline values and biological effects of seven metal species from different sites in this study were listed in Table 3 . It can be seen that the biological adverse effect of zinc is very serious in Lake-DT and posses the highest risk among the metals studied. Generally there is universal highly biological risk for zinc in the whole lake. The biological effect of $\mathrm{Cd}$ is high only at site $\mathrm{S} 1$ and S6. There are serious biological risk for As at site S4, S5 and S6. As to other metals of the seven heavy metals and sites, the effects are not too serious.

Table 3. ERL (the effects range-low, $\mathrm{mg} / \mathrm{kg}$ ) and ERM (the effects range-median, $\mathrm{mg} / \mathrm{kg}$ ) for the incidence of biological adverse effects (\%) and the assessment results of seven heavy metals at different sites.

\begin{tabular}{|c|c|c|c|c|c|c|c|c|}
\hline \multicolumn{3}{|c|}{ Guideline (mg/kg) } & \multicolumn{6}{|c|}{ Adverse effects (\%) } \\
\hline & ERL & ERM & \multicolumn{2}{|c|}{$<\mathrm{ERL}$} & \multicolumn{2}{|c|}{ ERL $\sim$ ERM } & \multicolumn{2}{|c|}{$>\mathrm{ERM}$} \\
\hline $\mathrm{Cu}$ & 34 & 270 & \multicolumn{2}{|c|}{9.4} & \multicolumn{2}{|c|}{29.1} & \multicolumn{2}{|c|}{83.7} \\
\hline $\mathrm{Ni}$ & 20.9 & 51.6 & \multicolumn{2}{|c|}{1.9} & \multicolumn{2}{|c|}{16.7} & \multicolumn{2}{|c|}{16.9} \\
\hline $\mathrm{Pb}$ & 46.7 & 218 & \multicolumn{2}{|c|}{8.0} & \multicolumn{2}{|c|}{35.8} & \multicolumn{2}{|c|}{90.2} \\
\hline $\mathrm{Cr}$ & 81 & 370 & \multicolumn{2}{|c|}{2.9} & \multicolumn{2}{|c|}{21.1} & \multicolumn{2}{|c|}{95} \\
\hline $\mathrm{Cd}$ & 1.2 & 9.6 & \multicolumn{2}{|c|}{6.6} & \multicolumn{2}{|c|}{36.6} & \multicolumn{2}{|c|}{65.7} \\
\hline $\mathrm{Zn}$ & 150 & 410 & \multicolumn{2}{|c|}{6.1} & \multicolumn{2}{|c|}{47.0} & \multicolumn{2}{|c|}{69.8} \\
\hline As & 8.2 & 70 & \multicolumn{2}{|c|}{5.0} & \multicolumn{2}{|c|}{11.1} & \multicolumn{2}{|c|}{63.0} \\
\hline \multicolumn{9}{|c|}{ Adverse effects (\%) of each metal at different sample site } \\
\hline & S1 & S2 & S3 & S4 & S5 & S6 & S7 & S8 \\
\hline $\mathrm{Cu}$ & 29.1 & 29.1 & 9.4 & 29.1 & 29.1 & 9.4 & 29.1 & 9.4 \\
\hline $\mathrm{Ni}$ & 16.7 & 1.9 & 1.9 & 16.7 & 1.9 & 1.9 & 16.7 & 1.9 \\
\hline $\mathrm{Pb}$ & 35.8 & 8.0 & 35.8 & 8.0 & 8.0 & 35.8 & 35.8 & 8.0 \\
\hline $\mathrm{Cr}$ & 21.1 & 2.9 & 2.9 & 2.9 & 2.9 & 2.9 & 21.1 & 2.9 \\
\hline $\mathrm{Cd}$ & 65.7 & 6.6 & 36.6 & 6.6 & 6.6 & 65.7 & 6.6 & 6.6 \\
\hline $\mathrm{Zn}$ & 69.8 & 47.0 & 69.8 & 69.8 & 69.8 & 69.8 & 69.8 & 69.8 \\
\hline As & 5.0 & 5.0 & 11.1 & 63.0 & 63.0 & 63.0 & 5.0 & 11.1 \\
\hline
\end{tabular}

There are many methods for the environmental assessment on heavy metal pollution of the sediments (McCauley et al., 2000). When certain method is applied to assess the pollution extent of heavy metals, the factors including pollution caused by human, geo-chemical background value and the formation and rotten effects of rock in nature that may change the background value of one metal element should be considered roundly. Index of geo-accumulation $\left(\mathrm{I}_{\mathrm{geo}}\right)$ was suggested for assessment of the contamination of heavy metal in sediment from the view of environ-geography chemistry (see Equation-1). The assessing method with $\mathrm{I}_{\text {geo }}$ is simple, convenient and practicable (Muller, 1969). 


$$
\mathrm{I}_{\mathrm{geo}}=\log _{2}\left[\mathrm{C}_{\mathrm{n}} /\left(1.5 \times \mathrm{B}_{\mathrm{n}}\right)\right] \quad(\text { Equation-1) }
$$

Where: Cn-the real concentration of one metal element in sediment, $\mathrm{mg} / \mathrm{kg}$, Bn-the geo-chemical background values of the metal element, $\mathrm{mg} / \mathrm{kg}$. The coefficient 1.5 is used to revise the rotten affects.

The geo-chemical background value of each heavy metals used in the assessment is listed in Table 4, and the corresponding relationships between Igeo and the pollution levels are given in Table 5.

Table 4. Geo-chemical background values of heavy metals (mg/kg).

\begin{tabular}{ccccccccccc}
\hline Element & $\mathrm{Cu}$ & $\mathrm{Zn}$ & $\mathrm{Co}$ & $\mathrm{Ni}$ & $\mathrm{Mn}$ & $\mathrm{V}$ & $\mathrm{As}$ & $\mathrm{Cr}$ & $\mathrm{Cd}$ & $\mathrm{Pb}$ \\
\hline $\begin{array}{c}\text { Value } \\
(\mathrm{mg} / \mathrm{kg})\end{array}$ & 22.6 & 74.2 & 12.7 & 26.9 & 583 & 82.4 & 11.2 & 61 & 0.097 & 26 \\
\hline
\end{tabular}

Note: The geo-chemical background value of each heavy metal in soil of China was used here.

Table 5. Index of geo-accumulation $\left(\mathrm{I}_{\mathrm{geo}}\right)$ and their corresponding pollution levels.

\begin{tabular}{|c|c|c|c|c|c|c|}
\hline$I_{\text {geo }}$ & $>5$ & $>4 \sim 5$ & $>3 \sim 4$ & $>2 \sim 3$ & $>1 \sim 2$ & $>($ or $=) 1$ \\
\hline Level & $\begin{array}{l}\text { Very } \\
\text { High }\end{array}$ & $\begin{array}{c}\text { Very } \\
\text { High } \\
\sim \text { High }\end{array}$ & High & $\begin{array}{c}\text { High } \\
\sim \text { Moderate }\end{array}$ & Moderate & $\begin{array}{c}\text { Moderate } \\
\sim \text { No }\end{array}$ \\
\hline
\end{tabular}

Through calculation according to Equation-1, the Igeo of each heavy metal at different site in Lake-DT is obtained and listed in Table 6. There is no or only very light pollution for $\mathrm{Cu}, \mathrm{Co}, \mathrm{Ni}, \mathrm{Mn}, \mathrm{V}$ and $\mathrm{Cr}$ in the whole lake with the exception of certain moderate pollution at $\mathrm{S} 1, \mathrm{~S} 5$ and $\mathrm{S} 7$ for $\mathrm{Cu}$. But there is seriously wide contamination for $\mathrm{Zn}$ at the levels from terribly high to moderate in the whole lake. The contamination of $\mathrm{Zn}$ is more severe at the sites (S1, S6 and S7) close to the inlets of the main rivers (Lishui River, Yuang River, $\mathrm{Zi}$ River and Xiangjiang River). Those rivers flow through the metal mining and manufacture regions and collect into Lake-DT, so the contamination relates closely to the industries and their discharging of industrial wastewater and solid waste along the rivers. The contamination level of As is high in S4, S5 and S6, it should relate to the production of As in some manufacturers along the upriver (Lishui River, Yuan River and $\mathrm{Zi}$ River). For the notorious pollutants $\mathrm{Cd}$, terribly high contamination was found only in S1, S3 and S6, it implies there are some extreme strong pollution spots where materials containing $\mathrm{Cd}$ are probably being applied.

There is serious heavy metal contamination for $\mathrm{Zn}, \mathrm{Pb}$ and $\mathrm{Cd}$ in sediments from Lake-DT on the basis of the above two basically accordant assessments. Those sites contaminated more severe are almost near to the inlets of the four rivers con- 
Table 6. Index of geo-accumulation ( $\mathrm{I}_{\mathrm{geo}}$ ) of each metal element at different sampling sites.

\begin{tabular}{ccccccccc}
\hline & $\mathrm{S} 1$ & $\mathrm{~S} 2$ & $\mathrm{~S} 3$ & $\mathrm{~S} 4$ & $\mathrm{~S} 5$ & $\mathrm{~S} 6$ & $\mathrm{~S} 7$ & $\mathrm{~S} 8$ \\
\hline $\mathrm{Cu}$ & 1.18 & 0.99 & -0.3 & 0.62 & 1.16 & -1.12 & 1.22 & -0.5 \\
$\mathrm{Zn}$ & 5.33 & 1.5 & 5.6 & 2.88 & 3.40 & 6.33 & 6.15 & 2.29 \\
$\mathrm{Co}$ & 0.02 & -0.95 & -0.26 & -0.29 & -0.07 & -0.72 & -0.28 & -1.37 \\
$\mathrm{Ni}$ & 0.04 & -2.11 & -1.56 & -0.92 & -0.94 & -1.78 & -0.54 & $\mathrm{ND}$ \\
$\mathrm{Mn}$ & 1.99 & 0.3 & 0.54 & 0.47 & 0.03 & -0.17 & 0.93 & -0.33 \\
$\mathrm{~V}$ & 0.4 & -0.8 & -4.02 & -0.004 & -0.24 & 0.11 & 0.31 & -1.57 \\
$\mathrm{As}$ & $\mathrm{NA}$ & $\mathrm{NA}$ & 1.86 & 3.77 & 3.69 & 4.12 & $\mathrm{ND}$ & 2.08 \\
$\mathrm{Cr}$ & 0.29 & -0.53 & -0.39 & -0.19 & -0.16 & -0.53 & -0.03 & -1.34 \\
$\mathrm{Cd}$ & 6.86 & $\mathrm{NA}$ & 4.63 & $\mathrm{NA}$ & $\mathrm{NA}$ & 6.31 & $\mathrm{NA}$ & $\mathrm{NA}$ \\
$\mathrm{Pb}$ & 2.4 & -0.64 & 1.66 & $\mathrm{NA}$ & -2.42 & 2.34 & 2.39 & $\mathrm{NA}$ \\
\hline
\end{tabular}

Note: NA is not available.

necting and traversing through the industrial areas, suggesting the heavy metal contamination maybe relates closely to the industries of metal mining, metallurgy and manufacturing in this region. The control and treatment of the heavy metal contamination in Lake-DT especially for $\mathrm{Zn}$ seem very urgent. To control the discharging of industries of metal mining and manufacturing is maybe the principal measure for the local government.

Acknowledgments. This study was supported by National Basic Research Program of China (2003CB415006).

\section{REFERENCES}

Zoumis T, Schmidt A, Grigorova L, Calmano W (2001) Contaminants in sediments: remobilization and demobilization. Sci Tot Environ 266: 195-202

Tu J-W (2001) Hydrogeological present situation of regional environment in Dongtinghu district. Hunan Geol 20: 203-205 (in Chinese)

Zhu S-Q, Zang X-P (2001) Status and characteristics of heavy metals pollution in main cities along Yangtze River. Yangtze River 32: 23-25 (in Chinese)

Long ER, MacDonald DD, Smith SL, Calder FD (1995) Incidence of adverse biological effects within ranges of chemical concentrations in marine and estuarine sediments. Environ Manage 19: 81-97

McCauley DJ, DeCraeve GM, Linton TK (2000) Sediment quality guidelines and assessment: overview and research needs. Environ Sci Policy 3: 133-144

Muller G (1969) Index of geo-accumulation in sediments of the Rhine River. Geol J 2: 108-118 